\title{
Correction to: A multicenter randomized trial to assess the efficacy of CONvalescent plasma therapy in patients with Invasive COVID-19 and acute respiratory failure treated with mechanical ventilation: the CONFIDENT trial protocol
}

\author{
Benoît Misset $^{1 *}$ (D) Eric Hoste ${ }^{2}$, Anne Françoise Donneau ${ }^{3}$, David Grimaldi ${ }^{4}$, Geert Meyfroidt ${ }^{5}$, \\ Michel Moutschen ${ }^{6}$, Veerle Compernolle ${ }^{7}$, André Gothot ${ }^{8}$, Daniel Desmecht ${ }^{9}$, Mutien Garigliany ${ }^{9}$, \\ Tome Najdovski ${ }^{10}$ and Pierre François Laterre ${ }^{11}$
}

\section{Correction to: BMC Pulm Med (2020) 20:317 https://doi.org/10.1186/s12890-020-01361-x}

Following publication of the original article [1], it was brought to the authors' attention that sentences in the method section were not appropriate, due to an omission in the update of a prior version.

Namely, the following sentences have been deleted in the corrected version:

"Specifically, the interim assessment of the SOC group will be based on the numbers of patients and of deaths shown in Table 2. The recommendation will be made to stop accruing patients in the SOC group if the number of deaths observed in this group suggests a true mortality rate in excess of 0.4 . The rule for $D S M B$ recommendation shown in Table 2 will not be binding."

The original article can be found online at https://doi.org/10.1186/s12890020-01361-x

\footnotetext{
*Correspondence: benoit.misset@chuliege.be

'Department of Intensive Care Medicine, Liege University Hospital,

Domaine Universitaire du Sart Tilman, 4020 Liège, Belgium
}

Full list of author information is available at the end of the article
Table 2 has been removed, and table 3 has been renamed as "Table 2" in the corrected body text. The error has since been corrected in the original article.

Similarly, in the electronic supplement,

- the following sentences have been deleted:

"Specifically, the interim assessment of the SOC group will be based on the numbers of patients and of deaths shown in Table 1. The recommendation will be made to stop accruing patients in the SOC group if the number of deaths observed in this group suggests a true mortality rate in excess of 0.4 . The rule for DSMB recommendation shown in Table 1 will not be binding."

- Table 1 has been removed, and Table 2 has been renamed as "Table 1" in the corrected body text.

- the word "three" has been replaced by "two" in the following sentence, (paragraph 9.10):

"Because of the considerable uncertainties about the outcomes that will be observed in the two arms of the trial, the DSMB will be allowed to recommend design 
changes based on the observed data at the times of the interim analyses."

The authors apologize for any inconvenience caused.

\section{Author details}

'Department of Intensive Care Medicine, Liege University Hospital, Domaine Universitaire du Sart Tilman, 4020 Liège, Belgium. ${ }^{2}$ Department of Intensive Care Medicine, Gent University Hospital, Gent, Belgium. ${ }^{3}$ Biostatistic Unit, Public Health Department, Liège University, Liège, Belgium. ${ }^{4}$ Department of Intensive Care Medicine, Cliniques Universitaires de Bruxelles - Erasme, Université Libre de Bruxelles, Brussels, Belgium. ${ }^{5}$ Department of Intensive Care Medicine, University Hospitals Leuven, Leuven, Belgium. ${ }^{6}$ Department of Infectious Diseases, Liege University Hospital, Liège, Belgium. 'Blood Services

from the Red Cross, Mechelen, Belgium. ${ }^{8}$ Department of Immunohematology, Liege University Hospital, Liège, Belgium. ${ }^{9}$ Department of Animal Pathology, Liège University, Liège, Belgium. ${ }^{10}$ Blood Services From the Red Cross, Suarlée, Belgium. ${ }^{11}$ Department of Intensive Care Medicine, Saint-Luc University Hospital, Brussels, Belgium.
Published online: 26 July 2021

\section{Reference}

1. Misset B, Hoste E, Donneau AF, et al. A multicenter randomized trial to assess the efficacy of CONvalescent plasma therapy in patients with Invasive COVID-19 and acute respiratory failure treated with mechanical ventilation: the CONFIDENT trial protocol. BMC Pulm Med. 2020;20:317. https://doi.org/10.1186/s12890-020-01361-X.

\section{Publisher's Note}

Springer Nature remains neutral with regard to jurisdictional claims in published maps and institutional affiliations.
Ready to submit your research? Choose BMC and benefit from:

- fast, convenient online submission

- thorough peer review by experienced researchers in your field

- rapid publication on acceptance

- support for research data, including large and complex data types

- gold Open Access which fosters wider collaboration and increased citations

- maximum visibility for your research: over $100 \mathrm{M}$ website views per year

At BMC, research is always in progress.

Learn more biomedcentral.com/submissions 